tuberculosis in those who have not had the benefit of immunological protection. Complacency in the face of this seemingly satisfactory progress must now give way to concern at the decline in the rate of improvement of morbidity, as the continued incidence of new infection roveals increasing evidence of infection by drug-resistant organisms, and new drugs must be found to wage war anew on the ravages of this disease.

By contrast, the problem of the under-privileged nations is, as always, one of economics. The under-fed and under-nourished millions, unable to afford adequate medical supplies of drugs from abroad and ill-equipped to manufacture their own, are still the worst affected, and in such conditions the disease can and still does reach epidemic proportions. Drug costs are clearly of major importance, and the best drugs are seldom the cheapest. Even the lowest-cost treatment, with 'Isoniazid', which has recently been estimated at no more than 1.85 dollars per person per year, may be beyond the poorest nations if large numbers are involved, while treatment with alternative drug combinations, costing in some cases as much as $255 \cdot 5$ dollars per person per year, is well beyond the means of the average individual in even the most affluent of countries, and capable of placing a severe burden on the best of all nationalized health services. All nations, rich or poor, have a stake in the control of tubercu. losis in a world where high-speed international communica. tion undoubtedly contributes to the transfer of infection from one community to another, and the book edited by Dr. V. C. Barry presents an internationally-based appraisal of present-day progress in the chemotherapy of the disease.

The outstanding need is clearly for a better understanding of the phenomenon of drug resistance and the development of new drugs to combat resistant organisms. The incidence of drug resistance, its avoidance by the use of combination drug therapy, and the limitations of this approach are admirably summarized from the clinician's point of view by $\mathrm{N}$. Rist. The passive acceptance of its inevitability as a simple mutation phenomenon without thought or question of the fundamental biochemical lesion which must clearly be involved is both disturbing and surprising. On the other hand, the ever-increasing wealth of knowledge of the biochemistry of Mycobacterium tuberculosis, so well summarized by J. Asselineau and E. Lederer, provides a more hopeful augury for the solution of the all-important questions surrounding the mode of action of tuberculostatic drugs and the development of resistance to them. But, excellent as this account is, it is to be regretted that these contributors were not permitted greater freedom to expand a contribution which has such fundamental significance for future progress in the chemotherapy of tuberculosis. Despite such omissions, however, Chemotherapy of Tuberculosis provides an excellont survey of the present state of knowledge and will be welcomed by all interested in the fight against tuberculosis.

J. B. STENLAKE

\section{MODELS AND THEORIES FOR BIOLOGY}

Progress in Biocybernetics

Vol. 1. Edited by Norbert Wiener and J. P. Schadé. Pp. $\mathrm{x}+204$. (Amsterdam, London and New York: Elsevier Publishing Company, 1964.) $70 s$.

THIS is the first volume of a series on biocyberneties.

In the words of the editors. "Biocybernetics aims principally to construct models and theories in a manner which derives the functions of human beings and animals as those operating in organisms themselves". It is a subject which aims at supplying models-particularly 'dynamic' models-of biological systems; but not one of the articles achieves this end more completely than that by Dr. R. M. Stewart on "Adaptable Cellular Nets". In that particularly interesting article, Dr. Stewart summarizes a form of development which leans, in some part, on the original work of Dr. S. T. Bok and Dr. B. L.M. Chapman. This is indeed a worth-while development in the field of cybernetics.

The book as a whole is broken down into four sections. The first section is entitled "Cybernetics of the Endocrine System"; the second section is devoted to "Cybernetics and Audiology"; the third is devoted to "Cybernetics of Cell Systems". This includes the article by Dr. Stewart and especially interesting articles by Dr. Bok and Dr. Iversen. Finally, the fourth section contains general aspects of biocybernetics. This section includes interesting articles by G. Pask, Dr. David and Dr. Rashevsky.

The whole symposium is concerned with eyberneties and its relationship to the biological sciences, especially that part of biology which is concerned with medicine. It is an interesting and important contribution to the literature and, therefore, will be of great interest to anyone concerned with the field of biocybernetics. One of the difficulties in this field is the sparseness of the literature. Cybernetics offers techniques of analysis which one would expect to find being used in other aspects of biological science. That it is not reflects a lack of understanding, on the part of biologists, of what cyberneties is about. It also reflects the fact that too many biologists, like scientists in other fields, are too concerned with the discovery of experimental data, without being prepared to provide the necessary integrated theoretical background. It is one of the sad features of modern scientific development that theory is too often divorced from practice, an attitude that reflects again the belief held by so many scientists that science can develop by the accumulation of facts alone. Volume 1 of Progress in Biocybernetics itself suffers as a result and we find a certain inevitable lack of coherence in the articles when taken as a whole.

In spite of the difficulties inherent in the development of biocyberneties -it is really in its infancy-there is no doubt about it that this is an exciting publication and could be the source of tremendous stimulation to biologists looking for new modes of thought. It is especially recommended as reading for the mathematically inclined biologist.

F. H. George

\section{ANGIOSPERM EMBRYOLOGY}

Recent Advances in the Embryology of Angiosperms Edited by P. Maheshwari. Pp. x+467. (Delhi: International Society of Plant Morphologists, the University, 1963.) n.p.

THE scope of Recent Advances in the Embryology of Angiosperms is far wider than its title suggests. It extends in fact from a discussion of the structure of ovules to an account of the factors controlling the formation of fruits. Also considered, in addition to embryology proper, are the development of the male and female gametophytes, fertilization, the artificial culture of ovaries, and the peculiarities of endosperms. The volume has been inspired by Prof. Maheshwari. He provides a scholarly introduction to thirteen able contributions. There are also copious references, in themselves a valuable key to a scattered literature.

One of the striking features of contemporary research has clearly been the success with which the reproductive structures of angiosperms have been cultured in isolation. Fertilization and seed formation have even occurred in these conditions, and it seems only a matter of time and patient oxperimentation before it becomes possible to grow the gametophytes of angiosperms, as those of ferns, free from the sporophyte. This will, of course, enormously 